\title{
Sensitivity of naturally occurring coliphages to type I and type II restriction and modification
}

\author{
Ryszard Korona, $\dagger$ Barbara Korona $\dagger$ and Bruce R. Levin* \\ Department of Zoology, University of Massachusetts, Amherst, MA 01003, USA
}

(Received 20 August 1992; revised 4 January 1993; accepted 8 February 1993)

\begin{abstract}
Protection against lethal infections by bacteriophage may seem the most likely role of restriction-modification $(\mathrm{R}-\mathrm{M})$ systems in bacteria and the reason for their evolution. There are, however, phenomena which question this phage-mediated selection hypothesis for the maintenance of extant $\mathrm{R}-\mathrm{M}$ systems. Most prominent among these are the mechanisms phage have to avoid or otherwise limit the effects of the restriction endonucleases produced by their host bacteria. To evaluate the importance of these antirestriction mechanisms in Escherichia coli, we have examined the sensitivity of coliphage from natural and laboratory sources to a series of type I and II R-M systems. The results of our study indicate that, in vivo, restriction endonucleases have no effect on a substantial fraction of naturally occurring coliphage. The absence of restriction sites appears to be the most common reason why these phage are unaffected by type II restriction endonucleases, but other antirestriction mechanisms also operate. On the other hand, the frequency of naturally occurring coliphage sensitive to restriction appears sufficiently great for phage-mediated selection to be a viable hypothesis for the maintenance of $\mathrm{R}-\mathrm{M}$ in $E$. coli and its accessory elements.
\end{abstract}

\section{Introduction}

Restriction endonucleases recognize specific short sequences of bases, 'restriction sites', and cut DNA at these sites or other places. In vivo, this results in the destruction of foreign DNA infecting bacteria that product restriction endonucleases, and these enzymes were discovered because they can protect bacteria from bacteriophage infections (Luria \& Human, 1952; Arber, 1965).

The counterpart of restriction is modification. Bacteria that produce restriction endonucleases also alter their DNA to protect it from these enzymes. This is usually accomplished by the addition of methyl groups to cytosines or adenines in the restriction sites. For type I restriction endonucleases, the restriction and modification functions are performed by subunits of the same enzyme, and the DNA is cut at places other than the recognition site. For the other major functional group, type II, the restriction endonuclease and methyl-

* Author for correspondence. Present address: Department of Biology, Emory University, Atlanta, GA 30322, USA. Tel. (404) 727 2826; fax (404) 727 2880; email biobrl@emuvml.cc.emory.edu.

Abbreviation: $\mathrm{R}-\mathrm{M}$, restriction-modification. transferase responsible for modification are separate enzymes, and the DNA is cut at the site of recognition (Bickle, 1987). With probabilities ranging from $10^{-1}$ to $10^{-8}$, depending on the system, the methyltransferases responsible for protecting the bacterium's own DNA may methylate the DNA of an infecting phage before it is destroyed by the cell's restriction endonucleases. The virus is then able to complete its lytic cycle and the DNA of its progeny are modified for growth on bacteria with that $\mathbf{R}-\mathbf{M}$ system.

Restriction endonucleases and their associated methyltransferases have been found in most major groups of Eubacteria and Archaebacteria and are encoded by genes carried on plasmids and prophage as well as chromosomes (Kessler \& Manta, 1990). Approximately 200 different restriction sites have now been identified (Wilson \& Murray, 1991). There is little or no DNA sequence homology among the genes coding for different type II restriction endonucleases, suggesting that these enzymes with the same apparent function have evolved independently many times. Curiously, the methyltransferases associated with the type II restriction endonucleases appear to have evolved separately from these DNA-cutting enzymes and have many fewer ancestors (Wilson, 1990; Wilson \& Murray, 1991).

On first consideration, it would seem that $\mathrm{R}-\mathrm{M}$ 
systems evolved, and are maintained, to protect bacteria against infections by foreign DNA and particularly those of lethal phage. Theory predicts that in the presence of phage there will be strong, frequency-dependent selection favouring bacteria with novel $\mathbf{R}-\mathbf{M}$ systems (Levin, 1986). This kind of selection could account not only for the evolution and maintenance of $\mathrm{R}-\mathrm{M}$, but also for the considerable diversity of these systems. Empirically, however, there are at least two major caveats to accepting a phage-mediated selection hypothesis for maintaining $\mathrm{R}-\mathrm{M}$ in extant populations of bacteria.

While $\mathrm{R}-\mathrm{M}$ can provide bacteria with an initial advantage when invading communities in which phage are present, mutants that are either refractory to adsorption by these phage or resistant in other ways will rapidly evolve. Following the ascent of these resistant mutants, restriction will have little effect on the competition between different lineages of bacteria (Levin, 1988; Korona \& Levin, 1993; and see Discussion).

Phage have a number of mechanisms that seem to have evolved specifically to deal with the restriction endonucleases of their host bacteria. In a review, Kruger \& Bickle (1983) conclude that 'antirestriction mechanisms of one kind or another have been found in practically every phage that has been examined.' Included among these restriction-avoiding and -evading mechanisms are: (i) inhibition of restriction enzymes by phage-encoded proteins that are either injected along with the phage DNA or expressed by the host following infection; (ii) virus-encoded self-modification of DNA; (iii) phage stimulation of host modification functions; (iv) unusual DNA bases such as those in T-even coliphages, or glucosylation of bases; (v) phage-encoded products which destroy host endonuclease cofactors; and (vi) the absence of recognition sites for specific restriction endonucleases (Kruger \& Bickle, 1983; Sharp, 1986).

To evaluate the importance of antirestriction mechanisms in natural communities of $E$. coli, we isolated coliphages from sewage and tested their in vivo sensitivity and that of laboratory phages to restriction and modification by a variety of type I and type II R-M systems. We also estimated the number of restriction sites in the DNA of these wild coliphages for the type II restriction endonucleases used. We discuss the implications of the results for the hypothesis that E. coli $\mathrm{R}-\mathrm{M}$ systems are maintained by phage-mediated selection.

\section{Methods}

Bacteria, $R-M$ systems, plasmids and laboratory phage. Table 1 lists the bacterial strains employed in this study, their relevant genetic markers, and the names and restriction sites of the R-M systems examined. Two of the three type I systems considered, $E c o \mathrm{~B}$ and $E c o \mathrm{~K}$, are encoded by chromosomal genes and the gene for the third, EcoDXX, is carried on a naturally occurring plasmid (Caugant et al.,
1981; Piekarowicz \& Goguen, 1986). The four type II R-M systems considered here were encoded by genes carried on cloning plasmids; EcoRV, NdeI and Sbol3 on pUC19, and the fourth, PvuII, on pBR322. The plasmids coding for these type II $\mathbf{R}-\mathbf{M}$ systems were generously provided by Dr J. Benner of New England Biolabs. Using the methods described in Sambrook et al. (1989) we attempted to transform $\mathrm{R}^{-} \mathrm{M}^{-}$ strains of $E$. coli $\mathrm{K}-12$ (1228) and $E$. coli $\mathrm{B}(\mathrm{B} / 6)$ with these R-Mencoding plasmids. Except for our attempt to move pBR322/PvuII to $\mathrm{B} / 6$, all of these transformations were successful. The conjugative plasmid carrying EcoDXX was transferred by mating, at room temperature, with 1228 and a nitrosoguanadine-induced $\mathrm{Lac}^{-}$mutant of $\mathrm{B} / 6$, and selecting for the Lac marker on this plasmid.

We examined the following laboratory strains of phages for sensitivity to restriction and modification: Lambda-vir (a mutant of the temperate phage $\lambda$ that is insensitive to the repressor protein), T1X, T2, $\mathrm{T} 3, \mathrm{~T} 4, \mathrm{~T} 5, \mathrm{~T} 6$ and $\mathrm{T} 7$. The phage $\mathrm{T} 1 \mathrm{X}$ has the same host range as $\mathrm{T} 1$ and, based on other characters, appears to be a derivative of this phage, but unlike wild-type $\mathrm{T} 1$, does not cause contamination problems (Korona \& Levin, 1993). T1X, T2, T4, and T7 were obtained from Dr C. Thorne (Univ. Massachusetts, Amherst), Lambda-vir from N. Kleckner (Harvard Univ., Cambridge, MA), and T3, T5 and T6 from I. Molineux (Univ. Texas, Austin).

Culture and sampling methods. All bacterial cultures were grown at $37^{\circ} \mathrm{C}$ in $50 \mathrm{ml}$ Erlenmeyer flasks containing $10 \mathrm{ml}$ Luria-Bertani (LB) broth with agitation at between 150 and 200 r.p.m. After overnight incubation, $0.1 \mathrm{ml}$ of the culture was used to inoculate $3 \mathrm{ml}$ soft (top) agar which was overlaid on plates containing broth agar. The recipes for these culture and sampling media can be found in Clowes \& Hayes (1968) or Levin et al. (1977).

Phage lysates were prepared by suspending single plaques in about $1 \mathrm{ml} \mathrm{LB}$ containing a drop of chloroform. These were then diluted and mixed with host cells in soft agar. After incubation, the top agar was scraped off, mixed with LB and centrifuged at 10000 r.p.m. in a Eppendorf Microfuge for $15 \mathrm{~min}$. Two drops of chloroform were added to the supernatant to kill the bacteria. Phage titres were estimated from plaque counts on soft agar lawns of the $\mathbf{R}^{-} \mathbf{M}^{-}$and $\mathrm{R}^{+} \mathrm{M}^{+}$bacteria used in this study. All serial dilutions were made in $0.85 \%$ saline. Lysates were stored at $4{ }^{\circ} \mathrm{C}$.

Isolation and characterization of wild phage. Samples $(50 \mathrm{ml})$ were taken from the inflow of sewage treatment plants in three adjacent Massachusetts towns: Amherst, Hadley and Sunderland. They were treated with chloroform to kill the bacteria, and diluted and plated on lawns of $\mathrm{B} / 6 \mathrm{R}^{-} \mathrm{M}^{-}$and $1228 \mathrm{R}^{-} \mathrm{M}^{-}$. From each plate, we isolated several plaques with different morphologies and, using the above procedure, prepared single plaque lysates of each of these naturally occurring phage.

We characterized these wild phage by their host-range to a bank of $12 \mathrm{~B} / 6$ and 1228 strains resistant to different wild phages and the HaeII $\left(5^{\prime}-\mathrm{GG} \mid \mathrm{CC}-3^{\prime}\right)$ restriction fragment pattern of their DNA (Table 3 ). The procedure for molecular characterization of these phage is described below.

To determine whether a phage was lytic or temperate, we isolated potential lysogens from within the plaques and streaked them for single colonies on broth agar. This process of sequentially restreaking single colonies to separate them from contaminating extracellular phage was repeated for a total of six cycles. We then prepared liquid cultures with the purified colonies and assayed these cultures for the presence of free phage by planting them on lawns of the $\mathrm{R}^{-} \mathrm{M}^{-}$bacteria of isolation. Negative results, i.e. no free phage following this sequential recloning, were interpreted as evidence that the phage were lytic rather than temperate.

Isolation and restriction of phage DNA. Phage DNA was extracted by a 'plate lysate method' almost identical to that described by Sambrook 


\section{Table 1. Bacteria and plasmids}

B/6 was obtained from S. Lederberg (Brown University, Providence, RI, USA), B3 from C. Thorne, 1228 from L. Ballas (Loma Linda University, Los Angeles, CA, USA), CH50, Miller (1972) collection. pEcoDXX was isolated by us (Caugant et al., 1981). All plasmids with type II R-M systems were provided by J. Benner of New England Biolabs.

\begin{tabular}{|c|c|c|c|}
\hline & $\begin{array}{l}\mathrm{R}-\mathrm{M} \\
\text { type }\end{array}$ & Relevant markers & $\begin{array}{l}\text { Recognition sequence } \\
\qquad\left(5^{\prime}-3^{\prime}\right)\end{array}$ \\
\hline \multicolumn{4}{|l|}{ Bacterial strains } \\
\hline $\mathrm{B} / 6(\mathrm{~B})$ & $\mathbf{R}^{-} \mathbf{M}^{-}$ & ara rps $t s x$ & \\
\hline $\mathrm{B} / 61 \mathrm{ac} \mathrm{c}^{-}$(B) & $\mathbf{R}^{-} \mathbf{M}^{-}$ & ara lac rps tsx $r^{-} m^{-}$(B) & \\
\hline $1228(\mathrm{~K} 12)$ & $\mathrm{R}^{-} \mathbf{M}^{-}$ & thr leu lac nal $r^{-} m^{-}(\mathrm{K})$ & \\
\hline B3 (B) & Type I & $\operatorname{lac} \mathbf{R}^{+} \mathbf{M}^{+}(E c o \mathbf{B})$ & TGA(N) $)_{8}$ TGCT \\
\hline CSH50 (K12) & Type I & $\Delta$ (lacpro) rps nal $\mathrm{R}^{+} \mathrm{M}^{+}($Eco $\mathrm{K})$ & AAC $(N)_{6}$ GTGC \\
\hline \multicolumn{4}{|l|}{$R-M$ system on a plasmid } \\
\hline EcoRVRM8.7-2 & Type II & Amp & GAT $\mid$ ATC \\
\hline NdeIRM6.8-A6 & Type II & Amp & CA|TATG \\
\hline PvuIIRM8.7-M15 & Type II & Amp Tet & CAG|CTG \\
\hline SboC13RM8.1-A1 & Type II & Amp & TCG|CGA \\
\hline
\end{tabular}

Table 2. Source, host-range (bacteriotype) and plaque morphology of naturally occurring ('wild') phages

\begin{tabular}{|c|c|c|c|c|c|}
\hline Phage & Place* & $\begin{array}{l}\text { Lawn of } \\
\text { isolation }\end{array}$ & $\begin{array}{c}\text { Host-range } \\
\text { (bacteriotype) } \dagger\end{array}$ & $\begin{array}{l}\text { Restriction } \\
\text { fragment pattern }\end{array}$ & $\begin{array}{c}\text { Plaque } \\
\text { morphology }\end{array}$ \\
\hline a & A1 & $\mathrm{B} / 6$ & I & Unique & M \\
\hline $\mathrm{b}$ & $\mathrm{Al}$ & $\mathrm{B} / 6$ & II & Unique & vS \\
\hline $\mathrm{c}$ & A1 & $\mathrm{B} / 6$ & III & Unique & $\mathrm{L}$ \\
\hline $\mathrm{d}$ & A2 & $\mathrm{B} / 6$ & IV & Unique & M \\
\hline e & A2 & $\mathrm{B} / 6$ & $\mathrm{~V}$ & Not cut & $\mathrm{S}$ \\
\hline $\mathrm{f}$ & $\mathrm{A} 2$ & $\mathrm{~B} / 6$ & VI & Not cut & $S$ \\
\hline $\mathrm{g}$ & A2 & $\mathrm{B} / 6$ & VII & Unique & $\mathbf{M}$ \\
\hline $\mathrm{h}$ & $\mathrm{A} 2$ & 1228 & VIII & Not cut & $\mathrm{S}$ \\
\hline $\mathrm{i}$ & $\mathrm{A} 3$ & B $/ 6$ & IX & Unique & $\mathrm{M}$ \\
\hline $\mathrm{j}$ & A3 & $\mathrm{B} / 6$ & III & Unique & vS \\
\hline $\mathrm{k}$ & A3 & 1228 & I & Unique & $\mathrm{vL}$ \\
\hline 1 & $\mathrm{~A} 3$ & 1228 & $\mathrm{X}$ & Unique & $\mathrm{M}$ \\
\hline $\mathrm{m}$ & HI & $\mathrm{B} / 6$ & XI & Unique & $\mathrm{L}$ \\
\hline $\mathrm{n}$ & H1 & $\mathrm{B} / 6$ & II & Unique & $\mathrm{S}$ \\
\hline o & Hl & $\mathrm{B} / 6$ & XII & Unique & L \\
\hline $\mathrm{p}$ & H1 & $\mathrm{B} / 6$ & IX & Not cut & M \\
\hline $\mathrm{r}$ & $\mathrm{Hl}$ & $\mathrm{B} / 6$ & XIII & Unique & $\mathrm{vS}$ \\
\hline$s$ & $\mathrm{H} 2$ & $\mathrm{~B} / 6$ & XII & Unique & M \\
\hline $\mathrm{t}$ & $\mathrm{H} 2$ & 1228 & VII & Unique & $\mathrm{S}$ \\
\hline $\mathrm{u}$ & $\mathrm{H} 2$ & 1228 & $\mathrm{x}$ & Unique & $\mathbf{M}$ \\
\hline $\mathrm{w}$ & S1 & $\mathrm{B} / 6$ & XII & Unique & $\mathbf{M}$ \\
\hline $\mathrm{x}$ & $\mathrm{S} 1$ & $\mathrm{~B} / 6$ & III & Unique & $S$ \\
\hline$y$ & $\mathrm{~S} 1$ & 1228 & XIV & Unique & $\mathrm{L}$ \\
\hline $\mathrm{z}$ & S1 & 1228 & $X V$ & Unique & $\mathrm{M}$ \\
\hline
\end{tabular}

* Place and time of isolation: A1, Amherst, April 1986; A2, Amherst, July 1991; A3, Amherst, October 1991; H1, Hadley, July 1991; H2, Hadley, October 1991; S1, Sunderland, October 1991. $\dagger$ See Table 3 .

$\ddagger$ vS, very small; $\mathrm{S}$, small; $\mathrm{M}$, medium; L, large; vL, very large.

et al. (1989). This procedure was modified by the addition of several phenol extractions steps before the final extraction with phenol/ chloroform and chloroform. The buffers and incubation protocols for digesting phage DNA with restriction endonucleases were similar to those recommended by their supplier, New England Biolabs. However, for the wild phage we used higher concentrations of enzyme and substantially longer digestion times than suggested. Electrophoresis of the digested DNA was in $0.7 \%$ agarose (EEO, CMS brand) with a TBE buffer (Sambrook et al., 1989). The gels were stained with ethidium bromide, washed, and photographed on a UV box. In addition to HaeIII, the DNA of each of these phages was treated with the EcoRV, NdeI, PvuII, and NruI (an isoschizomer of Sbol3). The Sbol3 
Table 3. Host-range of phages on $R^{-} M^{-} E$. coli $B(B / 6)$ and $R^{-} M^{-} E$. coli $K-12(1228)$ and their derivatives selected for resistance to different wild phages

\begin{tabular}{|c|c|c|c|c|c|c|c|c|c|c|c|c|c|}
\hline \multirow[b]{2}{*}{ Phage } & \multirow[b]{2}{*}{ Bacteriotype } & \multirow{2}{*}{$\begin{array}{c}\text { Stock } \\
\text { B/6 }\end{array}$} & \multicolumn{6}{|c|}{$\mathrm{B} / 6$ resistant to: } & \multirow{2}{*}{$\begin{array}{c}\text { Stock } \\
\text { K12 }\end{array}$} & \multicolumn{4}{|c|}{ K12 resistant to: } \\
\hline & & & $\mathrm{a}$ & $\mathrm{b}$ & $\mathrm{c}$ & $\mathrm{e}$ & $\mathrm{m}$ & $\mathrm{p}$ & & $\mathrm{h}$ & $\mathrm{n}$ & o & $\mathbf{r}$ \\
\hline $\mathrm{a}$ & I & - & $\mathrm{r}$ & $\mathrm{r}$ & - & - & - & - & - & - & $r$ & - & - \\
\hline b & II & - & - & $\mathrm{r}$ & - & - & - & - & - & - & $r$ & - & - \\
\hline c & III & - & - & - & $r$ & - & - & - & $\mathrm{r}$ & $\mathrm{r}$ & $r$ & $\mathbf{r}$ & $r$ \\
\hline $\mathrm{d}$ & IV & - & - & - & - & - & - & $\mathrm{r}$ & - & - & - & - & - \\
\hline $\mathrm{e}$ & $\mathrm{V}$ & - & - & - & - & $r$ & - & - & - & - & - & - & - \\
\hline f & VI & - & - & - & - & $r$ & - & - & $r$ & $r$ & $r$ & $r$ & $r$ \\
\hline $\mathrm{g}$ & VII & - & - & - & - & - & - & - & - & - & - & - & - \\
\hline $\mathrm{h}$ & VIII & $\mathrm{r}$ & $\mathrm{r}$ & $\mathbf{r}$ & $r$ & $\mathrm{r}$ & $\mathrm{r}$ & $\mathrm{r}$ & - & $\mathrm{r}$ & - & - & - \\
\hline i & IX & - & - & - & - & - & - & $r$ & $r$ & $r$ & $\mathrm{r}$ & $\mathrm{r}$ & $\mathrm{r}$ \\
\hline $\mathrm{j}$ & III & - & - & - & $\mathbf{r}$ & - & - & - & $\mathrm{r}$ & $\mathrm{r}$ & $r$ & $\mathrm{r}$ & $\mathrm{r}$ \\
\hline $\mathrm{k}$ & I & - & $r$ & $r$ & - & - & - & - & - & - & $\mathrm{r}$ & - & - \\
\hline 1 & $\mathrm{X}$ & $\mathrm{r}$ & $\mathrm{r}$ & $r$ & $r$ & $\mathrm{r}$ & $r$ & $\mathbf{r}$ & - & - & - & - & - \\
\hline $\mathrm{m}$ & XI & - & - & - & - & - & $\mathrm{r}$ & - & - & - & - & - & - \\
\hline $\mathrm{n}$ & II & - & - & $r$ & - & - & - & - & - & - & $r$ & - & - \\
\hline o & XII & - & - & - & - & - & - & - & - & - & - & $\mathrm{r}$ & - \\
\hline $\mathrm{p}$ & IX & - & - & - & - & - & - & $\mathrm{r}$ & $\mathrm{r}$ & $\mathrm{r}$ & $\mathbf{r}$ & $\mathrm{r}$ & $\mathrm{r}$ \\
\hline $\mathrm{r}$ & XIII & - & - & $\mathrm{r}$ & - & - & - & - & - & - & $\mathrm{r}$ & - & $\mathrm{r}$ \\
\hline $\mathrm{s}$ & XII & - & - & - & - & - & - & - & - & - & - & $r$ & - \\
\hline $\mathrm{t}$ & VII & - & - & - & - & - & - & - & - & - & - & - & - \\
\hline $\mathrm{u}$ & X & $\mathrm{r}$ & $\mathrm{r}$ & $\mathrm{r}$ & $r$ & $r$ & $r$ & $\mathrm{r}$ & - & - & - & - & - \\
\hline$w$ & XII & - & - & - & - & - & - & - & - & - & - & $\mathrm{r}$ & - \\
\hline $\mathrm{x}$ & III & - & - & - & $\mathrm{r}$ & - & - & - & $\mathrm{r}$ & $\mathrm{r}$ & $r$ & $\mathrm{r}$ & $\mathrm{r}$ \\
\hline$y$ & XIV & - & $r$ & - & - & - & - & - & - & - & - & - & - \\
\hline $\mathrm{z}$ & XV & - & $\mathrm{r}$ & - & $r$ & - & - & - & - & - & $r$ & - & - \\
\hline
\end{tabular}

r, Resistant: no plaques on lawns of that bacterial stock.

- , Sensitive: plaques on lawns of that bacterial stock.

restriction endonuclease is not available commercially. A minimum of two independent DNA preparations and gels were run for each phage.

\section{Results}

The wild phages

The source, host-range ('bacteriotype'), HaeIII restriction type and plaque morphology of the 24 wild phages isolated from the sewage samples are summarized in Table 2. The details of the host-ranges of these wild phage are given in Table 3 . These 24 phage from six different samples had 15 distinct host-range patterns and 20 unique restriction-fragment patterns. All 24 of these phage were lytic rather than temperate on the $E$. coli $\mathrm{K}$ 12 and $\mathrm{B}$ hosts studied here.

There is a great deal of cross-resistance (Table 3). Out of ten strains of $E$. coli $\mathrm{B}$ and $\mathrm{K}-12$ selected for resistance to single wild phages, seven were also resistant to one or more additional wild phage(s). The proportion of crossresistance could be even higher than indicated here, as the stock $\mathrm{B} / 6\left(\mathrm{R}^{-} \mathrm{M}^{-}\right.$E. coli $\left.\mathrm{B}\right)$ is resistant to three of the wild phages and stock $1228\left(\mathrm{R}^{-} \mathrm{M}^{-}\right.$E. coli $\left.\mathrm{K}-12\right)$ is resistant to six of them.

The DNA of four of these phages (e, $f, h$ and $p$ ) was not cut by HaeIII (Table 2). This negative result could be explained in a number of non-trivial ways. One of these phages, $p$, is likely to have double-stranded DNA as its genetic material. It is sensitive to EcoRV and $S b o 13$ restriction and modification in vivo (Table 5), but for reasons we do not know, its DNA is not readily isolated by this protocol. One possibility is that the DNA of this phage replicates as a double-stranded molecule, but is packaged as single-stranded DNA. Ethidium bromide does not stain single-stranded DNA. The other three phages for which we were unable to get HaeIII digests (e, $\mathrm{f}$, and $\mathrm{h}$ ) were also insensitive to all the tested type I and type II restriction enzymes in vivo. We believe they are DNA phages, as after treatment with RNAase there is still a substantial amount of ethidium bromide staining. One possible reason for their DNA not being cut is that these phages have unusual or glucosylated bases, like the $\mathrm{T}$-even laboratory phages.

The HaeIII restriction fragment pattern of the DNAs of each of these phages was compared to all others at least twice. Not counting the three phages for which we were unable to get $\mathrm{HaeIII}$ digests and which were also insensitive to the tested $\mathrm{R}-\mathrm{Ms}$ in vivo $(\mathrm{e}, \mathrm{f}$, and $\mathrm{h}$ ), there are a total of 21 wild phages with unique HaeIII restriction-fragment patterns. Considering the hostrange as well as the molecular characterization, all 24 phages listed in Table 2 are unique. 
Table 4. In vivo restriction efficiency $R$ of laboratory phages

Data shown are means of two independent estimates. Bold numbers indicate that restriction and modification was observed in both replicas. The ' $\mathrm{E}$ ' indicates that the number immediately preceding is to be multiplied by 10 to the power of the number following the ' $E$ ' (exponent).

\begin{tabular}{|c|c|c|c|c|c|c|c|}
\hline Phage & $E c o \mathbf{B}$ & EcoK & $E c o \mathrm{DXX}$ & $E c o \mathrm{RV}$ & NdeI & PvuII & Sbo 13 \\
\hline Lambda & $48 \mathrm{E}-3$ & $6 \cdot 0 E-3$ & $3 \cdot 7 E-5$ & $2 \cdot 3 E-6$ & $2 \cdot 8 E-2$ & $1.6 E-4$ & $1.8 E-4$ \\
\hline $\mathrm{T} 1 \mathrm{X}$ & $1 \cdot 1 E+0$ & $1.0 \mathrm{E}+0$ & $4 \cdot 1 E-4$ & $9 \cdot 1 E-4$ & $1 \cdot 1 E+0$ & -* & $6 \cdot 8 E-5$ \\
\hline $\mathrm{T} 2$ & $9 \cdot 3 E-1$ & $1 \cdot 2 \mathrm{E}+0$ & $8 \cdot 3 E-1$ & $5 \cdot 5 \mathrm{E}-1$ & $6.5 E-1$ & $1 \cdot 4 \mathrm{E}+0$ & $8 \cdot 0 \mathrm{E}-1$ \\
\hline $\mathrm{T} 3$ & $1 \cdot 4 \mathrm{E}+0$ & $1 \cdot 3 E+0$ & $1 \cdot 5 \mathrm{E}+0$ & $1 \cdot 2 \mathrm{E}+0$ & $8 \cdot 5 E-1$ & $5 \cdot 2 E-6$ & $1 \cdot 6 E-4$ \\
\hline $\mathrm{T} 4$ & $1 \cdot 0 \mathrm{E}+0$ & $1 \cdot 1 E+0$ & $6 \cdot 6 \mathrm{E}-1$ & $5 \cdot 0 \mathrm{E}-1$ & $6 \cdot 6 \mathrm{E}-1$ & $8 \cdot 4 E-1$ & $5 \cdot 5 \mathrm{E}-1$ \\
\hline T5 & $9 \cdot 9 \mathrm{E}-1$ & $9 \cdot 8 \mathrm{E}-1$ & $9 \cdot 8 \mathrm{E}-1$ & $1 \cdot 1 \mathrm{E}+0$ & $9 \cdot 9 \mathrm{E}-1$ & $-^{*}$ & $1 \cdot 3 E+0$ \\
\hline T6 & $9 \cdot 9 \mathrm{E}-1$ & $7 \cdot 8 \mathrm{E}-0$ & $6 \cdot 9 \mathrm{E}-1$ & $6.9 \mathrm{E}-1$ & $6 \cdot 1 \mathrm{E}-1$ & $8 \cdot 8 E-1$ & $1 \cdot 3 \mathrm{E}+0$ \\
\hline $\mathrm{T} 7$ & $1 \cdot 0 \mathrm{E}+0$ & $1 \cdot 7 \mathrm{E}+0$ & $7 \cdot 5 E-1$ & $1 \cdot 0 \mathrm{E}+0$ & $3.6 E-2$ & $1 \cdot 7 E-3$ & $1.8 E-2$ \\
\hline
\end{tabular}

${ }^{*}$ E. coli $\mathrm{K}-12 \mathrm{R}^{-} \mathrm{M}^{-}$strain 1228 was resistant to $\mathrm{T} 5$.

\section{Sensitivity to $R-M$ systems in vivo and in vitro}

As a measure of the sensitivity of these phage to restriction in vivo, we defined the ratio of their plating efficiency on $\mathbf{R}^{+} \mathbf{M}^{+}$and $\mathbf{R}^{-} \mathbf{M}^{-}$lawns as their 'restriction efficiency' $(R)$

$$
R=\frac{\left(\text { Titre on } \mathrm{R}^{+} \mathrm{M}^{+}\right)}{\left(\text {Titre on } \mathrm{R}^{-} \mathrm{M}^{-}\right)}
$$

The $\mathbf{R}^{-} \mathbf{M}^{-}$and $\mathbf{R}^{+} \mathbf{M}^{+}$bacteria used for these estimates of restriction efficiency of the laboratory phages are noted in the legend to Table 4 . For wild phages, the $\mathrm{B} / 6$ or 1228 strain used on the lawn of isolation (Table 2) was subsequently used as the $\mathrm{R}^{-} \mathbf{M}^{-}$bacteria and, with the $\mathrm{R}-\mathrm{M}$-encoding plasmids, as the $\mathrm{R}^{+} \mathrm{M}^{+}$bacteria for estimates of $R$. Exceptions to this were made for PvuII, where all phages had to be plated on 1228. As noted earlier, we were unable to move the $P v u I I$-bearing plasmid to $\mathrm{B} / 6$.

When the restriction efficiency $R$ was greater than 0.5 in two independent tests, the phage was designated insensitive to that $\mathrm{R}-\mathrm{M}$ system. When in both these tests $R<0.5$, the phage was considered to be potentially sensitive to that restriction system and was subsequently tested for modification by that $\mathrm{R}-\mathrm{M}$ system. The latter was done by removing single plaques from the $R^{+} \mathbf{M}^{+}$ lawn, suspending the phage in LB with chloroform and, without further growth, estimating their densities on the same $\mathrm{R}^{+} \mathrm{M}^{+}$and $\mathrm{R}^{-} \mathbf{M}^{-}$lawns. This time, we considered $R>0.5$ in two independent replicas as evidence for modification. All of the phages presumed sensitive to the restriction endonuclease of an $\mathrm{R}-\mathrm{M}$ system by the $R<$ 0.5 criterion also showed evidence for modification by that system.

In Table 4, we present the mean values of $R$ for the laboratory phages with all the tested type I and II R-M systems. As expected, because of their unusual bases and glucosylation, T2, T4 and T6 were not affected by any of
Table 5. In vivo restriction efficiency $R$ of wild phage to type I $R-M$ systems

Gaps (-) indicate that the $\mathbf{R}^{-} \mathbf{M}^{-}$strain was resistant to that phage. All data are means of two independent estimates. Bold numbers indicate that restriction and modification was observed in both replicas.

\begin{tabular}{|c|c|c|c|}
\hline Phage & EcoB & EcoK & $E c o \mathrm{DXX}$ \\
\hline $\mathrm{a}$ & $3 \cdot 1 E-05$ & $7 \cdot 2 \mathrm{E}-01$ & $4 \cdot 5 E-05$ \\
\hline b & $1 \cdot 3 E+01$ & $9.8 \mathrm{E}-01$ & $1 \cdot 2 \mathrm{E}+00$ \\
\hline c & $8 \cdot 9 \mathrm{E}-01$ & $1 \cdot 1 \mathrm{E}+00$ & $8.9 E-03$ \\
\hline $\mathrm{d}$ & $1 \cdot 1 \bar{E}+00$ & $1 \cdot 8 E+00$ & $6 \cdot 7 \mathrm{E}-01$ \\
\hline $\mathrm{g}$ & $8 \cdot 0 \mathrm{E}-01$ & $1 \cdot 6 \mathrm{E}+00$ & $9.0 E-03$ \\
\hline i & $1 \cdot 7 \mathrm{E}+00$ & $1 \cdot 6 \mathrm{E}+00$ & $1 \cdot 2 \mathrm{E}+00$ \\
\hline $\mathrm{j}$ & $1 \cdot 2 \mathrm{E}+00$ & $2 \cdot 1 \mathrm{E}+00$ & $9 \cdot 5 \mathrm{E}-01$ \\
\hline $\mathrm{k}$ & $3.0 E-06$ & $7 \cdot 1 \mathrm{E}-01$ & $1.8 E-04$ \\
\hline 1 & $8 \cdot 6 \mathrm{E}-01$ & $6 \cdot 7 \mathrm{E}-01$ & $8 \cdot 9 \mathrm{E}-01$ \\
\hline $\mathrm{m}$ & $9 \cdot 4 \bar{E}-01$ & $8 \cdot 1 \bar{E}-01$ & $1.6 \mathrm{E}-01$ \\
\hline $\mathrm{n}$ & $8 \cdot 5 E-01$ & $1 \cdot 7 \mathrm{E}+00$ & $1 \cdot 1 E+00$ \\
\hline o & - & $1 \cdot 0 \mathrm{E}-02$ & $7 \cdot 2 E-04$ \\
\hline $\mathrm{p}$ & $7 \cdot 2 \mathrm{E}-01$ & - & $1 \cdot 3 E+00$ \\
\hline $\mathrm{r}$ & $2 \cdot 0 \mathrm{E}+00$ & $1 \cdot 4 \mathrm{E}+00$ & $1 \cdot 1 \mathrm{E}+00$ \\
\hline s & - & $1.5 E-05$ & $5 \cdot 4 E-04$ \\
\hline $\mathrm{t}$ & $1 \cdot 3 E-05$ & $1 \cdot 1 \mathrm{E}+00$ & $4 \cdot 7 E-07$ \\
\hline $\mathrm{u}$ & - & $8 \cdot 1 \mathrm{E}-01$ & $8 \cdot 4 \mathrm{E}-01$ \\
\hline $\mathrm{w}$ & - & $1.0 \mathrm{E}+00$ & $6.8 E-03$ \\
\hline $\mathrm{x}$ & $1 \cdot 0 \mathrm{E}+00$ & $1 \cdot 4 E+00$ & $1 \cdot 6 \mathrm{E}+00$ \\
\hline $\mathrm{y}$ & $8 \cdot 1 E-06$ & $9 \cdot 4 E-01$ & $2 \cdot 8 E-03$ \\
\hline $\mathrm{z}$ & $1 \cdot 3 E-03$ & $7 \cdot 7 \mathrm{E}-01$ & $1 \cdot 7 \mathrm{E}+00$ \\
\hline
\end{tabular}

the type I or type II enzymes considered. T5 was also unaffected. Lambda-vir was sensitive to all of these $\mathbf{R}-\mathbf{M}$ systems. T1X, T3 and T7 were sensitive only to the plasmid-borne R-Ms, the type I EcoDXX and some type IIs. The restriction efficiencies of these $\mathrm{R}-\mathrm{M}$-sensitive laboratory phages ranged from approximately $2 \times 10^{-1}$ to $5 \times 10^{-6}$.

Table 5 shows $R$ values for the type I R-M systems with the 21 wild phages. The frequency of wild phage sensitive to the plasmid-borne EcoDXX restriction is $0 \cdot 43 \pm 0 \cdot 11$ (frequency, $P \pm \mathrm{SEM}$ or $P \pm[P(1-P) / N]^{1 / 2}$, 
Table 6. In vivo restriction efficiency $R$ and estimated number of restriction sites for wild phage and type II $R-M$ systems

Gaps (-) indicate that the $\mathbf{R}^{-} \mathbf{M}^{-}$strain and/or the $\mathbf{R}^{+} \mathbf{M}^{+}$was resistant to that phage or, in the case of the phage $p$, the DNA could not be properly prepared. All data are means of two independent estimates. Bold numbers indicate that restriction and modification was observed in both replicas. In calculating the number of restriction sites, we assumed linear DNA.

\begin{tabular}{|c|c|c|c|c|c|c|c|c|}
\hline \multirow[b]{2}{*}{ Phage } & \multicolumn{2}{|c|}{$E c o \mathrm{RV}$} & \multicolumn{2}{|c|}{$N d e \mathrm{I}$} & \multicolumn{2}{|c|}{ Sbol3 } & \multicolumn{2}{|c|}{ PvuII } \\
\hline & Ratio & Sites & Ratio & Sites & Ratio & Sites & Ratio & Sites \\
\hline a & $7 \cdot 6 \mathrm{E}-01$ & 0 & $9 \cdot 6 \mathrm{E}-01$ & 0 & $2 \cdot 0 \mathrm{E}-0.5$ & 12 & $1.9 \mathrm{E}-0.8$ & 2 \\
\hline $\mathrm{b}$ & $6 \cdot 3 E-01$ & 0 & $1 \cdot 1 \mathrm{E}+00$ & 14 & $1 \cdot 0 \mathrm{E}+00$ & 1 & $6.9 E-01$ & 8 \\
\hline c & $5.9 E-04$ & 12 & $6 \cdot 3 \mathrm{E}-01$ & 0 & $1.8 E-05$ & 11 & - & 3 \\
\hline $\mathrm{d}$ & $1.9 E-07$ & 15 & $7 \cdot 8 \mathrm{E}-01$ & 3 & $8 \cdot 0 E-07$ & 15 & - & 3 \\
\hline g & $5 \cdot 6 E-05$ & 1 & $5 \cdot 2 \mathrm{E}-01$ & 0 & $4 \cdot 3 E-08$ & 10 & $1.8 E-07$ & 1 \\
\hline $\mathrm{i}$ & $1 \cdot 2 \mathrm{E}+00$ & 0 & $1 \cdot 2 \mathrm{E}+00$ & 0 & $9 \cdot 6 \mathrm{E}-01$ & 2 & - & 13 \\
\hline j & $2 \cdot 8 E-05$ & 22 & $1 \cdot 3 E+00$ & 0 & $1.9 E-02$ & 2 & - & 7 \\
\hline $\mathrm{k}$ & $9 \cdot 1 \mathrm{E}-01$ & 0 & $7 \cdot 2 \mathrm{E}-02$ & 5 & $1.0 \mathrm{E}-07$ & 14 & $1.0 E-03$ & 4 \\
\hline 1 & $1.9 E-05$ & 21 & $3 \cdot 1 E-02$ & 13 & $7.8 E-04$ & 2 & $3 \cdot 0 \mathrm{E}-05$ & 21 \\
\hline $\mathrm{m}$ & $1 \cdot 1 E-02$ & 5 & $7 \cdot 2 \mathrm{E}-01$ & 0 & $6 \cdot 3 \mathrm{E}-01$ & 0 & $5 \cdot 0 \mathrm{E}-01$ & 13 \\
\hline $\mathrm{n}$ & $4 \cdot 5 E-04$ & 20 & $8 \cdot 1 \mathrm{E}-01$ & 0 & $2 \cdot 0 E-04$ & 4 & $8 \cdot 6 E-03$ & 10 \\
\hline o & $1 \cdot 2 E-05$ & 8 & $2 \cdot 9 \mathrm{E}-01$ & 3 & $8.9 E-01$ & 0 & $9 \cdot 8 \mathrm{E}-01$ & 0 \\
\hline $\mathrm{p}$ & $1.9 E-04$ & - & $1 \cdot 0 \mathrm{E}+00$ & - & $6 \cdot 3 \mathrm{E}-02$ & - & - & - \\
\hline r & $2 \cdot 1 E-03$ & 4 & $1 \cdot 8 \mathrm{E}+00$ & 0 & $4 \cdot 1 E-01$ & 1 & $1 \cdot 1 E-01$ & 14 \\
\hline $\mathrm{s}$ & $2 \cdot 1 \mathrm{E}-06$ & 6 & $1.5 E-02$ & 2 & $6.8 E-05$ & 9 & - & 13 \\
\hline $\mathrm{t}$ & $2 \cdot 8 E-07$ & 9 & $3 \cdot 5 E-04$ & 2 & $5 \cdot 3 E-08$ & 5 & $6.8 E-08$ & 1 \\
\hline $\mathrm{u}$ & $4 \cdot 1 E-04$ & 22 & $2 \cdot 2 \mathrm{E}-02$ & 4 & $2 \cdot 5 E-06$ & 6 & $1 \cdot 7 E-04$ & 15 \\
\hline $\mathrm{w}$ & $1.8 E-06$ & 29 & $2 \cdot 2 \mathrm{E}-01$ & 3 & $2 \cdot 5 E-07$ & 20 & $4 \cdot 4 E-07$ & 1 \\
\hline $\mathrm{x}$ & $7 \cdot 8 \mathrm{E}-01$ & 0 & $9 \cdot 9 \mathrm{E}-01$ & 0 & $1.2 \mathrm{E}-02$ & 3 & - & 9 \\
\hline $\mathrm{y}$ & $1 \cdot 2 E+00$ & 0 & $4 \cdot 1 \mathrm{E}-02$ & 5 & $1 \cdot 2 E-07$ & 9 & $\mathbf{1} \cdot \mathbf{0 E}-07$ & 7 \\
\hline $\mathrm{z}$ & $5 \cdot 6 \mathrm{E}-05$ & 17 & $1 \cdot 2 \mathrm{E}-01$ & 12 & $4.9 E-05$ & 5 & $8.0 E-06$ & 18 \\
\hline
\end{tabular}

where $N$ is the number tested). For the $E c o$ B and $E c o K$ chromosomal type I restriction systems, the corresponding frequencies of $\mathbf{R}-\mathbf{M}$-sensitive wild phage were $0 \cdot 29 \pm 0 \cdot 11$ and $0 \cdot 10 \pm 0 \cdot 07$ respectively. The restriction efficiency of these phages to the tested type I R-Ms ranged from $10^{-2}$ to $3 \times 10^{-6}$.

Table 6 shows the sensitivity of wild phage to type II $\mathbf{R}-\mathbf{M}$ systems. The frequencies of the tested naturally occurring phages sensitive to these type II R-M systems were $0.71 \pm 0.10,0.43 \pm 0.11,0.81 \pm 0.09$ and $0.79 \pm 0.09$, for EcoRV, NdeI, Sbo 13 and PvuII, respectively. The efficiency of restriction $R$ of these wild phages on the tested type II R-M systems ranged from $10^{-1}$ to $2 \times 10^{-8}$.

Every wild phage that was sensitive to $\mathrm{R}-\mathrm{M}$ in vivo and was tested with that enzyme (or its isoschizomer) in vitro, had at least one restriction site. The corollary of this is not true. Of the 21 cases where both in vivo and in vitro tests for sensitivity to $\mathbf{R}-\mathbf{M}$ were performed and the in vivo criteria indicated resistance, 16 had no restriction sites, but five had three or more sites. The latter group included phages $b$ and $n$, which had 14 and 13 restriction sites for $N d e I$ and $P v u I I$, respectively, but were insensitive to those restriction endonucleases in vivo. Among phages sensitive to type II $\mathrm{R}-\mathrm{M}$ in vivo, there was no association between the extent of sensitivity $R$ and the estimated number of restriction sites. The correlation coefficients for relationship between the number of restriction sites and $R$, and $\log R$, were not significant $(P>0 \cdot 05)$.

\section{Discussion}

\section{Phage-mediated selection of $R-M$}

Experimental studies of the population dynamics of phage suggest that as a consequence of resistance, including resistance to multiple phage, $\mathrm{R}-\mathrm{M}$ provides only a transitory advantage to bacteria in established communities of bacteria and phage (Levin, 1988; Korona \& Levin, 1993). However, the same studies also indicate that a novel R-M system can considerably assist bacteria colonizing a new habitat in which phage are present. The magnitude of this 'colonization selection' advantage for a single bacterium can approach the reciprocal of the restriction efficiency, $1 / R$, which in this study ranged from 10 to $10^{8}$. Stated another way, R-M can substantially reduce the minimum population size (the colonization density) required for bacteria to establish populations in new habitats in which phage are present.

Whether colonization selection for $\mathbf{R}-\mathbf{M}$ actually operates in natural communities, and how effective it is, depends on the density of phage sensitive to the restriction systems borne by the invading $\mathrm{R}^{+} \mathbf{M}^{+}$bacteria. Our results suggest that, for $E$. coli, if phage are present 
at all, they are likely to be sensitive to one or more R-M systems. All but five of the 24 wild phages isolated were sensitive to at least one of the seven $\mathrm{R}-\mathrm{M}$ systems examined and usually more than one. Of 57 phage-type I R-M pairs tested in vivo, $26 \%$ were positive (showed evidence for restriction and modification); and of the 77 phage-type II R-M pairs tested, $68 \%$ were positive.

How general these results are depends on whether the phage and $\mathbf{R}-\mathbf{M}$ systems examined are representative of those in natural communities of $E$. coli and coliphage. We believe that the 24 wild coliphage studied here are representative. They were isolated from three different sewage treatment plants at different times of the year and were chosen because they could form plaques on $\mathrm{R}^{-} \mathbf{M}^{-}$ lawns of E. coli B or K-12, not because of their sensitivity or resistance to restriction. The results of our survey also suggest that the number of distinct coliphage types ('species') in sewage, as based on the bacteriotyping and molecular typing criteria employed here, is relatively large. We examined fewer than 50 phages to pick out the 24 distinct types.

The choice of R-M systems studied here was not based on information about the incidence and frequency of different R-M systems in naturally occurring $E$. coli. About eight distinct type I and 140 distinct type II restriction endonucleases with at least eight and 48 different restriction sites, respectively, have been identified in E. coli (Kessler \& Manta, 1990). However, the relative frequencies of these $\mathrm{R}-\mathrm{M}$ systems in natural populations are unknown. Furthermore, there is no reason to assume that $\mathrm{R}-\mathrm{M}$ systems from other bacterial species do not find their way into E. coli, especially when those systems are encoded by genes borne on plasmids. In any event, four of the seven $\mathrm{R}-\mathrm{M}$ systems considered here, $E c o \mathrm{~B}, E c o \mathrm{~K}, E c o \mathrm{DXX}$ and $E c o \mathrm{RV}$, were found in E. coli and one, Sbo 13, came from Shigella boydii, a close relative of E. coli. The other two, NdeI and PvuII, were derived from the Gram-negative bacteria Neisseria denitrificans and Proteus vulgaris.

The advantage $\mathrm{R}-\mathrm{M}$ provides to bacteria in the presence of phage would be inversely proportional to the $R$ values for these phages. The present study offers little information about the magnitude of such values for natural populations of E. coli. Although EcoB, EcoK and $E c o \mathrm{DXX}$ are naturally regulated, their levels of expression in the laboratory strains $E$. coli $\mathrm{K}-12$ and $E$. coli $\mathrm{B}$ may differ from those in naturally occurring $E$. coli. Not only are EcoRV, NdeI, PvuII and Sbo 13 systems in laboratory strains of $E$. coli, they are also borne on synthetically constructed plasmids. Finally, it is not at all clear how effective $\mathbf{R}-\mathbf{M}$ is when the producing $E$. coli are living in natural conditions rather than the artificial situation of exponential growth in broth.

To us, the major caveat to accepting the hypothesis that R-M systems in E. coli (and, by induction, other bacterial species) are maintained because of the protection they provide against phage is the dearth of quantitative information about the biology of natural populations of $E$. coli and its viruses (see review by Lenski, 1988). For the reasons described above, we believe that our results support the phage-mediated selection hypothesis for the maintenance of $\mathrm{R}-\mathrm{M}$. However, without more quantitative information on the natural population biology of $E$. coli and its phages, we believe that this hypothesis remains largely untested.

\section{(Co)evolution of antirestriction mechanisms}

For whatever reasons bacteria have evolved R-M systems, bacteriophage have to deal with them, and natural selection would be anticipated to favour mechanisms that enable these viruses to avoid or limit the effects of host restriction. Our results are consistent with this expectation. They support and add generality to Kruger \& Bickle's (1983) interpretation that many, perhaps the majority, of bacteriophage have one or more mechanisms to evade or otherwise limit the effects of some of the restriction endonucleases produced by their host bacteria. Only one of the seven $\mathrm{T}$ phages studied, a variant of $\mathrm{T} 1$, was sensitive to any of the three tested type I R-M systems. Although three of these T-phages were sensitive to one or more of the four type II R-M systems examined, none was sensitive to all four. Universal sensitivity to the tested type I and II R-M, of the sort noted for $\lambda$, was not seen for any of the naturally occurring phages examined. Of the 21 wild phages with DNAs that were sensitive to one or more restriction endonuclease in vitro, in vivo none were sensitive to all three of the studied type I R-M systems and only four were sensitive to all four of the type II R-M systems.

Whether the mechanisms these phage have for evading specific restriction endonucleases evolved specifically for that purpose, or are coincidental to some other selected function, cannot be answered with any assurance. For the phage studied here, the most obvious mechanism for avoiding type II $\mathbf{R}-\mathbf{M}$ is the absence of restriction sites. Three-quarters of the 21 cases of in vivo resistance to type II $\mathrm{R}-\mathrm{M}$ could be attributed to phage not having restriction sites for those enzymes. To ascertain whether the absence of these sites (six-base palindromes) can be attributed to chance, rather than selection for the loss of these sites, would require a more detailed consideration of the size and base composition of the DNA of these phages than seems warranted for the present study. However, the distribution of restriction sites for these 6cutter enzymes is clearly not random for many, if any, of the phage (Table 6). For example, for phage $j$, the number of restriction sites for these four enzymes ranged 
from 0 to 22, and for phage $\mathrm{n}$ this number ranged from 0 to 20 . To us, the most parsimonious explanation for the non-random distribution of restriction sites is restrictionendonuclease-mediated selection for their loss.

The absence of restriction sites is not, however, the only mechanism responsible for variation in in vivo sensitivity to specific type II restriction endonucleases. In five of the 21 cases of in vivo resistance to type II restriction endonucleases, the enzymes could cut the DNA of those phages in vitro. Indeed, in two of these cases, there were more than 13 restriction sites for those enzymes. A similar phenomenon has been reported for T5, which has six EcoRI restriction sites, and is not affected by EcoRI in vivo (reviewed in Kruger \& Bickle, 1983) or any of the seven R-M systems studied here.

It is difficult for us to interpret the observation that for the $\mathbf{R}-\mathbf{M}$-sensitive strains the efficiency of type II $\mathbf{R}-\mathbf{M}$ restriction $R$ is uncorrelated with the number of restriction sites. This lack of correlation might be an artifact of the unnatural expression of these R-M genes on synthetic plasmids, or could be a consequence of variations in the genome sizes and base ratios of these phage. Another more interesting possibility is that the majority of these phage have other antirestriction mechanisms. These phages are available and we would be delighted to send them to interested readers.

We wish to thank Jake Simpson for technical assistance and Sarah Gates and Carol Laursen for comments on the manuscript reporting these results. We are particularly grateful to Jack Benner and New England Biolabs for making the EcoRV-, NdeI-, Sbo13- and PvuIIencoding cloning plasmids available to us. This research was supported by a grant from the US National Institutes of Health, GM33782.

\section{References}

ARBER, W. (1965). Host controlled modification of bacteriophage. Annual Review of Microbiology 19, 365-368.
BiCKLE, T. A. (1987). DNA Restriction and modification systems. In: Escherichia coli and Salmonella typhimurium Cellular and Molecular Biology, pp. 692-696. Edited by F. C. Neidhardt. Washington DC: American Society of Microbiology.

Caugant, D. A., Levin, B. R. \& Selander, R. K. (1981). Genetic diversity and temporal variation in the $E$. coli populations of a human host. Genetics 98, 467-490.

Clowes, R. C. \& HAYEs, W. (1968). Experiments in Microbiol Genetics. New York: J. Wiley and Sons.

Kessler, C. \& MANTA, V. (1990). Specificity of restriction endonucleases and DNA modification transferases - a review (Edition 3 ). Gene 92, 1-248.

Korona, R. \& Levin, B. R. (1993). Phage-mediated selection and the evolution and maintenance of restriction-modification. Evolution 47, $565-575$.

Kruger, D. H. \& Bickle, T. A. (1983). Bacteriophage survival: multiple mechanisms for avoiding deoxyribonucleic acid restriction systems of their hosts. Microbiological Reviews 47, 345-360.

LENSKI, R. E. (1988). Dynamics of interactions between bacteria and virulent bacteriophage. Advances in Microbial Ecology 10, 1-44.

LEVIN, B. R. (1986). Restriction-modification and the maintenance of genetic diversity in bacterial populations. Conference on Evolutionary Processes and Theory, pp. 669-688. Edited by E. Nevo \& S. Karlin. New York: Academic Press.

Levin, B. R., Stewart, F. M. \& Chao, L. (1977). Resource limited growth, competition and predation. A model with some experimental studies with bacteria and bacteriophage. American Naturalist 111, $3-24$.

Levin, B. R. (1988). Frequency-dependent selection in bacterial populations. Philosophical Transactions of the Royal Society, London 319, 459-472.

LuRIa, S. E. \& Human, M. L. (1952). A non-hereditary host-induced variation in bacterial viruses. Journal of Bacteriology 64, 557-559.

Miller, J. H. (1972). Experiments in Molecular Genetics. Cold Spring Harbor, NY: Cold Spring Harbor Laboratory.

Piekarowicz A. \& Goguen, J. D. (1986). The DNA sequence recognized by the EcoDXXI restriction endonuclease. European Journal of Biochemistry 154, 295-298.

SambrooK, J., Fritsch, E. F. \& Maniatis, T. (1989). Molecular Cloning: a Laboratory Manual. Cold Spring Harbor NY: Cold Spring Harbor Laboratory.

SHARP, P. M. (1986). Molecular evolution of bacteriophage: evidence of selection against the recognition sites of host retriction enzymes. Molecular Biology and Evolution 3, 75-83.

WILSON, G. (1990). Organization of restriction-modification systems. Nucleic Acid Research 19, 2539-2566.

Wilson, G. G. \& Murray, N. E. (1991). Restriction and modification systems. Annual Review of Genetics 25, 585-627. 